\title{
Optimal management of collagenous colitis: a review
}

This article was published in the following Dove Press journal:

Clinical and Experimental Gastroenterology

10 February 2016

Number of times this article has been viewed

\section{Aoibhlinn O'Toole}

Department of Gastroenterology, Beaumont Hospital, Dublin, Ireland

Correspondence: Aoibhlinn O'Toole Department of Gastroenterology, Beaumont Hospital, Beaumont Road, Dublin 9, Ireland

Tel +353 I 8093194

Email aoibhlinn@hotmail.com
Abstract: Collagenous colitis (CC) is an increasingly recognized cause of chronic inflammatory bowel disease characterized by watery non-bloody diarrhea. As a lesser studied inflammatory bowel disease, many aspects of the CC's natural history are poorly understood. This review discusses strategies to optimally manage $\mathrm{CC}$. The goal of therapy is to induce clinical remission, $<3$ stools a day or $<1$ watery stool a day with subsequent improved quality of life (QOL). Antidiarrheal can be used as monotherapy or with other medications to control diarrhea. Budesonide therapy has revolutionized treatment and is superior to prednisone, however, the treatment is associated with high-relapse rates and the management of refractory disease is challenging. Ongoing trials will address the safety and efficacy of low-dose maintenance therapy. For those with refractory disease, case reports and case series support the role of biologic agents. Diversion of the fecal stream normalizes colonic mucosal changes and ileostomy may be considered where anti-tumor necrosis factor (TNF)- $\alpha$ agents are contraindicated. Underlying celiac disease, bile salt diarrhea, and associated thyroid dysfunction should be ruled out. The author recommends smoking cessation as well as avoidance of nonsteroidal anti-inflammatories as well as other associated medications.

Keywords: microscopic, collagenous, lymphocytic, colitis, diarrhea, budesonide, inflammatory bowel disease

\section{Introduction}

Microscopic colitis (MC) is an increasingly recognized cause of chronic inflammatory bowel disease characterized by watery non-bloody diarrhea. ${ }^{1}$ There are two main subtypes, collagenous colitis (CC) and lymphocytic colitis (LC), the hallmarks of which are a history of watery diarrhea, normal or near normal appearing colonic mucosa at endoscopy and characteristic microscopic features. ${ }^{2}$

It classically occurs in elderly women. Since the first description of a case of $\mathrm{CC}$ over three decades ago, ${ }^{3} \mathrm{MC}$ has been associated with celiac disease and other autoimmune disorders ${ }^{4,5}$ as well as with the use of certain medications, particularly nonsteroidal anti-inflammatory drugs (NSAIDs). ${ }^{6,7}$ Unlike the other inflammatory bowel diseases, many aspects of the condition's etiology, pathogenesis, and natural history remain poorly understood. Prior to the introduction of budesonide, the wide range of medications prescribed reflects the lack of specific guidelines for the treatment of MC. With few randomized trials available to guide management. ${ }^{8}$ Treatment was based predominantly on the individual preference and experience of the treating physician, taking into account the pattern and severity of symptoms and potential contraindications to the use of specific therapies. ${ }^{9} \mathrm{CC}$ is more clearly defined than $\mathrm{LC}$, 
furthermore, non-specific colonic lymphocyte infiltration is frequently encountered.

This review discusses strategies to optimally manage CC.

\section{Collagenous colitis Epidemiology}

CC was first described in 1976 when a thick subepithelial collagenous deposit in the colorectal mucosa was identified in a rectal biopsy from a patient with chronic diarrhea. ${ }^{3}$ It classically occurs in middle-aged females, with a peak incidence around 60-70 years of age but has been described in all age groups, including the pediatric population. ${ }^{10,11}$

An incidence of 5-10 per 100,000 has been described in population-based studies with a prevalence of CC in Olmsted County, MN, USA in 2010 of 90.4 per 100,000 and in Örebro, Sweden of 67.7 per $100,000 .^{12,13}$

A recent meta-analysis of 25 studies by Tong et al reports a pooled incidence rate of 4.14 per 100,000 person years with steadily increasing incidence rates until 2000, but since then stable rates have been observed in the USA, Spain, and Sweden. ${ }^{14}$ However, higher reports were reported in a 10 year Danish pathology study with annual incidence rates increasing from 2.9 to 14.9 per 10,000. This rise corresponded with an increase in biopsies taken and the authors conclude that this may represent increased diagnostic activity. ${ }^{15}$

A Korean study of chronic diarrhea detected CC in 4\% of patients similar to rates recorded in the western world ${ }^{16}$ and has been reported with lower prevalence rates in Indian and Malaysian studies. ${ }^{17,18}$

\section{Pathophysiology}

$\mathrm{CC}$ is a multifactorial disease, likely the result of an aberrant immune reaction to luminal antigens in predisposed individuals, with subsequent epithelial barrier dysfunction in the colonic mucosa. ${ }^{19}$

An aberrant $\mathrm{T}$ lymphocyte response is thought to drive chronic gut inflammation and a Th1 cytokine profile predominates with elevated levels of interferon- $\gamma$, tumor necrosis factor (TNF)- $\alpha$ and interleukin (IL)- $1 \beta \cdot{ }^{20}$ The mechanism of diarrhea has been attributed to reduced $\mathrm{Na}^{+}$and $\mathrm{Cl}^{-}$absorption accompanied by active $\mathrm{Cl}^{-}$secretion. Watery stools in $\mathrm{CC}$ are driven by a combination of osmotic and secretory components as well as impaired barrier function. ${ }^{21}$

Unlike Crohn's and ulcerative colitis there is little data to suggest genetic inheritance, however, there are reports of familial cases of CC. Two families are described, in each two first degree relatives develop CC and in all four patients the human leukocyte $\mathrm{A} 2$ antigen was detected. ${ }^{22}$
Variations in matrix metalloproteinase- 9 and TNF $\alpha$ gene expression have been described. ${ }^{23,24}$

Others postulate that $\mathrm{CC}$ occurs as a sequela to infectious colitis with the reports of development after Yersinia enterocolitica and Clostridium difficile infections. ${ }^{25,26}$ Furthermore, resolution of symptoms following treatment for Helicobacter pylori has been reported. ${ }^{27}$

The development of a thickened collagen band is attributed to abnormal collagen metabolism. Subepithelial matrix deposition is driven by increased expression of fibrogenic gene procollagen I and metalloproteinase inhibitor and promyofibroblastic cells as well as impaired fibrinolysis. ${ }^{28,29}$

Increased levels of eosinophils transforming growth factor beta expression have been demonstrated in patients with $\mathrm{CC}$, and this is thought to drive tissue collagen accumulation. ${ }^{30}$ Increased expression of nitric oxide synthase driven by upregulation of nuclear transcription factor beta results in increased colonic nitric oxide production, which in turn may cause a secretory diarrhea. ${ }^{31}$

\section{Symptoms}

The hallmark of CC is chronic watery diarrhea; other symptoms include abdominal pain, urgency fecal incontinence, abdominal pain, fatigue, and weight loss. ${ }^{32,33}$

$\mathrm{CC}$ is rarely associated with serious complications, however, cases of spontaneous and postcolonoscopy perforation have been reported ${ }^{34,35}$ and Bohr et al propose a connection between mucosal tears and colonic perforation in CC. ${ }^{34}$ Unlike chronic inflammation seen in ulcerative and Crohn's colitis, no increased risk of colorectal cancer has been attributed to $\mathrm{CC}$, furthermore, it may be protective against colorectal cancer. In a study of 305 patients undergoing colonoscopy for evaluation of chronic non-bloody diarrhea, $16 \%$ had MC, and patients with MC were negatively associated with the risk of neoplastic polyps. ${ }^{36}$

The clinical symptoms may be misdiagnosed as irritable bowel syndrome (IBS). A total of 247 who were diagnosed with diarrhea predominant irritable bowel underwent colonoscopy and $6 \%$ were subsequently diagnosed with MC (13 LC, 2 CC).$^{37}$ Interestingly, colonoscopies performed in patients who fulfilled diagnostic criteria for IBS were significantly more likely to find organic gastrointestinal pathology in those with diarrhea predominant symptoms, with MC diagnosed in $2.2 \%$ of patients. ${ }^{38}$ Additionally, there is considerable symptomatic overlap between both disorders..$^{39,40}$

Quality of life (QOL) was severely impaired in Swedish patients, particularly when the colitis is active compared to the background population. ${ }^{41}$ A Swedish case-control study 
subsequently demonstrated that abdominal pain, fatigue, arthralgia, myalgia, fecal incontinence, and nocturnal defecation were significantly more prevalent in CC patients compared with controls. ${ }^{42}$

\section{Risk factors}

Traditionally, MC was considered a condition of middle-aged women using aspirin and NSAIDs but now many classes of drugs including selective seratonin reuptake inhibitors, statins, proton pump inhibitors, topirimate, venotonic agents, and histamine antagonists have been associated with medication related colitides. ${ }^{6,32,43-45}$ This highlights the importance of taking a detailed history, as symptoms can resolve upon withdrawal of the offending agent. However, evidence supporting cause and effect is lacking, in fact, many of these medications list diarrhea as a side effect.

Smoking is consistently reported as an environmental risk factor in the development of CC. ${ }^{46-48}$ This may be related to impaired colonic circulatory changes. The smokers developed their disease $>10$ years earlier than nonsmokers, but smoking does not influence the subsequent disease course. ${ }^{49}$

The author recommends obtaining a detailed medication, diet, and smoking history to identify factors that may exacerbate symptoms, furthermore, coexisting causes of diarrhea (celiac disease or bile-salt diarrhea) should be considered.

Clinical characteristics, treatment and outcomes of $\mathrm{MC}$ in 222 patients was studied and a history of concomitant autoimmune disorders was recorded in 62 patients $(28 \%)$. Twenty-six patients (11\%) had either a known diagnosis of celiac disease or were diagnosed at the same time as their lower gastrointestinal examination. ${ }^{9}$ This underlines the particular importance of colonic biopsy in patients whose celiac disease remains symptomatic despite adherence to a gluten-free diet. Recently, data from a Canadian population study report a strong association between $\mathrm{MC}$ and celiac disease with concomitance being $\sim 50$ times that expected in the general population. ${ }^{50} \mathrm{~A}$ Spanish case-control study recently showed that autoimmune diseases were independently associated with the risk of $\mathrm{MC}$ development. ${ }^{46}$

\section{Diagnosis}

There are no reliable biomarkers, no specific laboratory tests, stool cultures are sterile and radiological findings are normal.

Fecal lactoferrin and calprotectin, which can be used as non-invasive markers of inflammation in ulcerative colitis and Crohn's disease are not reliable in the diagnosis or assessment of CC. ${ }^{51}$
Endoscopic evaluation of the colon can be normal, however, erythema, edema, change in vascularity, mucosal tears, and nodularity have been described. ${ }^{2,52-54}$

The diagnosis is made based on characteristic histological findings in colonic mucosal biopsies. The key histological feature of $\mathrm{CC}$ is a thickened collagen band under the surface epithelium..$^{55,56}$ The European consensus guidelines on diagnosis state that the thickness of the collagen band should exceed $10 \mu \mathrm{m}$ (normal $<3 \mu \mathrm{m}$ ) in well-oriented biopsies (cut perpendicularly to the mucosal surface). ${ }^{55}$ The band can appear thicker (up to $70 \mu \mathrm{m}$ ) and band thickness greater than $15 \mathrm{~mm}$ is usually associated with diarrhea, ${ }^{57}$ but there is no direct correlation between band thickness and symptoms.

Hematoxylin and eosin staining is sufficient for diagnosis in most cases. In questionable cases special collagen stains (blue trichrome, Goldner, and Sirius red) or immunohistochemistry with anti-tenascin antibodies are required for diagnosis. ${ }^{58}$

Findings can be patchy in nature, with colonic segments affected to varying extents. ${ }^{57}$ The subepithelial collagen band tends to be less thick in the distal colon, in particular the rectum and sigmoid colon. ${ }^{59,60}$ Carpenter et al demonstrated that in patients with proximal inflammation left-sided biopsies alone would have missed $40 \%$ of cases. ${ }^{61}$ Therefore, rectal and left-sided biopsies alone are insufficient for diagnosis. The best approach to diagnosis is obtaining multiple biopsies throughout the colon submitted as individual pathology specimens. ${ }^{62-64}$

\section{Treatment Goals of therapy}

No curative therapy currently exists for MC. The goal of therapy is to induce clinical remission, $<3$ stools a day or $<1$ watery stool a day with subsequent improved QOL. Prior to the introduction of budesonide, choice of treatment relied largely on the experience of the individual physician or institution and was based on observational data, with few randomized trials available to guide management; ${ }^{8}$ the few controlled trials that exist have mainly evaluated budesonide.

Hjortswang et al studied the impact of colonic symptoms on health-related QOL in CC and based on these defined criteria for remission and disease activity. ${ }^{65}$ QOL was impaired in those with a mean of $\geq 3$ stools/day or a mean of $\geq 1$ watery stool/day, therefore, the Hjortswang-Criteria propose that clinical remission in $\mathrm{CC}$ is defined as a mean of $<3$ stools/day and a mean of $<1$ watery stool per day and disease activity to be a daily mean of $\geq 3$ stools or a mean of $\geq 1$ watery stool (Table 1 ). 
Table I Hjortswang-Criteria definition of clinical disease activity in collagenous colitis

\begin{tabular}{llll}
\hline & \multicolumn{2}{l}{$\begin{array}{l}\text { Stools per day (mean } \\
\text { during I week) }\end{array}$} & $\begin{array}{l}\text { Watery stools per day } \\
\text { (mean during I week) }\end{array}$ \\
\hline Clinical remission & $<3$ & AND & $<1$ \\
Clinical activity & $\geq 3$ & OR & $\geq 1$
\end{tabular}

Notes: Adapted by permission of Oxford University Press from Munch A, Aust D, Bohr J, et al. Microscopic colitis: current status, present and future challenges: statements of the European Microscopic Colitis Group. Journal of Crohn's and Colitis. 2012;6(9):932-945. Copyright ๑ Oxford University Press. ${ }^{32}$

\section{Avoidance of environmental triggers}

Smoking cessation is recommended as well as withdrawal of medications associated with $\mathrm{CC}$ where possible. The author recommends a detailed medication history and where possible cessation of potentially provocative agents. ${ }^{66}$

\section{Symptomatic management of diarrhea}

For control of symptoms, loperamide is an effective treatment. Antidiarrheals can be used as monotherapy or with other medications to control diarrhea. ${ }^{67,68}$ Although these have not formally been subject to randomized placebo-controlled trials, they are considered first-line therapy in patients with mild symptoms for symptomatic response.

In patients with associated bile-acid malabsorption cholestyramine may be considered as cholestyramine may adhere to bacterial toxins that have been implicated in CC pathogenesis.

\section{Corticosteroids}

The use of prednisone in the management of CC is limited given inferior efficacy and increased side effect profile compared to budesonide.

Compared to budesonide, prednisone is associated with a lower response rate, more side effects, and a higher risk of relapse when therapy is withdrawn.

The clinical pathological effect of prednisolone was studied prospectively in six patients with CC. Prednisolone resulted in a transient decrease in stool frequency, with a trend toward decreased inflammatory changes in posttreatment biopsies but without resolution of the collagen band (except in one patient). ${ }^{69}$

Gentile et al compared clinical outcomes in 80 patients with MC (40 CC, $40 \mathrm{LC})$ treated with corticosteroids. ${ }^{70}$ Among samples, 17 were treated with prednisone (21.2\%) and 63 with budesonide (78.8\%). Significantly higher rates of clinical response were observed in the budesonide treatment group (82.5\% vs $52.9 \%$; odds ratio, 4.18 ; $95 \%$ confidence interval (CI), 1.3-13.5) with lower rates of recurrence after treatment discontinuation. Furthermore, a randomized, double-blind trial of short-term prednisolone $50 \mathrm{mg}$ or placebo demonstrated incomplete remission in nine patients. ${ }^{71}$ Therefore, prednisone therapy is not recommended as a first-line treatment for CC.

\section{Budesonide}

Budesonide remains the first-line therapy, significantly improving symptoms and QOL. It is a locally active corticosteroid that undergoes first-pass metabolism in the liver with subsequent low systemic exposure.

A systematic review of 10 randomized controlled trials concluded that budesonide was safe, effective, and well tolerated for induction and maintenance of clinical and histological remission; evidence for bismuth, prednisone, probiotics, mesalamine, and cholestyramine was weaker. ${ }^{72}$

When symptoms persist despite antidiarrheals the author suggests treatment with budesonide. A suggested approach is $9 \mathrm{mg}$ daily for $6-8$ weeks. If symptoms persist or recur budesonide $9 \mathrm{mg}$ can be used for 12 weeks and then tapered accordingly. Budesonide short-term therapy is safe and effective and can improve QOL. ${ }^{72-75} \mathrm{~A}$ meta-analysis of eight randomized trials that included 248 patients randomized to budesonide or placebo demonstrated that short-term clinical response rates were significantly higher with budesonide, as compared with placebo (risk ratio [RR] 3.1; 95\% CI, $2.1-4.6) .^{76}$

In a Phase III placebo-controlled, multicenter study, Miehlke et al studied budesonide and mesalamine as shortterm therapies for $\mathrm{CC} .{ }^{77}$ In a double-blind, double-dummy manner patients with active disease were treated with $9 \mathrm{mg}$ once daily budesonide $(\mathrm{n}=30), 3 \mathrm{~g}$ once daily mesalamine $(n=25)$, or placebo $(n=37)$ for 8 weeks. The primary endpoint was clinical remission ( $<3$ bowel motions a day).

After 8 weeks therapy, $84.8 \%$ of patients on budesonide were in clinical remission $(<3$ bowel motions a day) compared to $60.6 \%$ receiving placebo, using the HjortswangCriteria for clinical remission $80 \%$ of patients receiving budesonide therapy entered clinical remission compared to $37.8 \%$ of patients treated with placebo $(P=0.0006)$. Of those patients given mesalamine $44 \%$ achieved clinical remission, but superior outcomes were seen with budesonide ( $P=0.0035$ ). Furthermore, budesonide therapy was shown to improve histological scores, stool consistency and abdominal pain. There were no differences in adverse effects noted between treatment groups.

Budesonide has been shown to significantly reduce the histological inflammatory changes in $\mathrm{CC}$ with no change in the collagen thickness band, but a significant decrease in the lamina propria infiltrate. ${ }^{78}$ 
Using the Gastrointestinal Quality of Life Index tool, QOL in patients with CC randomized to budesonide or placebo was assessed and found that QOL scores are low in patients with CC, after 6 weeks of treatment with budesonide scores improved significantly compared to those receiving placebo. $^{79}$

\section{Recurrent symptoms and maintenance therapy}

Recurrence after budesonide treatment is common and can be retreated with budesonide as intermittent therapy or as continuous maintenance therapy ideally at the lowest dose that maintains clinical remission. ${ }^{76}$ However, low-dose maintenance treatment is controversial, mainly due to risk of steroid-related side effects.

Risk factors for relapse after budesonide withdrawal were assessed in 123 patients who achieved clinical remission with budesonide therapy for CC in controlled trials. ${ }^{80}$ The rate of relapse was $61 \%$. Risk factors associated with relapse included high-stool frequency at baseline and a long duration of diarrhea. Time to relapse was shorter in those with a baseline stool frequency of $>5$ per day and in those with a $>12$ month history of diarrhea. Budesonide maintenance therapy was a protective factor against recurring symptoms and maintenance therapy delayed time from relapse from 56 to 207 days.

In a randomized controlled trial assessing long-term outcomes of budesonide therapy clinical relapse occurred in $61 \%$ of patients after a median of 2 weeks and relapse occurred significantly more often in patients over the age of 60 years. ${ }^{80}$

A meta-analysis on the short- and long-term efficacy of corticosteroids in the treatment of MC of 248 patients from eight trials randomized to corticosteroids revealed that short- and long-term treatment with budesonide is effective and well tolerated for MC and was associated with clinical and histological response. ${ }^{76}$ Again, this confirmed high rates of symptom relapse (46\%-80\%) of patients within 6 months of treatment discontinuation.

A prospective randomized, placebo-controlled trial of low-dose budesonide (mean dose $4.5 \mathrm{mg}$ a day) for the maintenance of clinical remission in $\mathrm{CC}$ demonstrated that budesonide maintained clinical remission for at least 1 year in $61.4 \%$ (27/44 patients) compared to $16.7 \%$ (8/48 patients) receiving placebo (treatment difference $44.5 \%$ in favor of budesonide; 95\% CI [26.9\%-62.7\%], $P<0.001) .{ }^{81}$ There was a high-relapse rate after discontinuation $82.1 \%$ (23/28 patients). Overall treatment was well tolerated with no serious adverse events, and the authors conclude that treatment extension with low-dose budesonide beyond 1 year may be beneficial given the high-relapse rate after budesonide discontinuation.

\section{Refractory CC}

Ten to 20 percent of patients do not respond to budesonide therapy $^{74}$ and there is a paucity of data to guide therapy in those with refractory CC.

In those not responding to antidiarrheals and budesonide one should assess for other causes of chronic diarrhea, particularly celiac disease and thyroid dysfunction given the higher incidence of autoimmune diseases in the patient population. Persistent use of NSAIDS needs to be ruled out as well as IBS and bile salt diarrhea (Figure 1). ${ }^{32}$

An approach to those with mild symptoms who do not respond to budesonide is to use a combination treatment with loperamide and cholestyramine. If symptoms persist despite this strategy Bismuth subsalicylate could be considered, but availability is limited and use is limited by nephrotoxicity. ${ }^{82}$

\section{Cholestyramine}

Bile acid diarrhea is commonly associated with $\mathrm{CC}$ and in those patients with concomitant bile acid malabsorption cholestryramine is an effective therapy. ${ }^{83,84}$

Active collagenous colitis

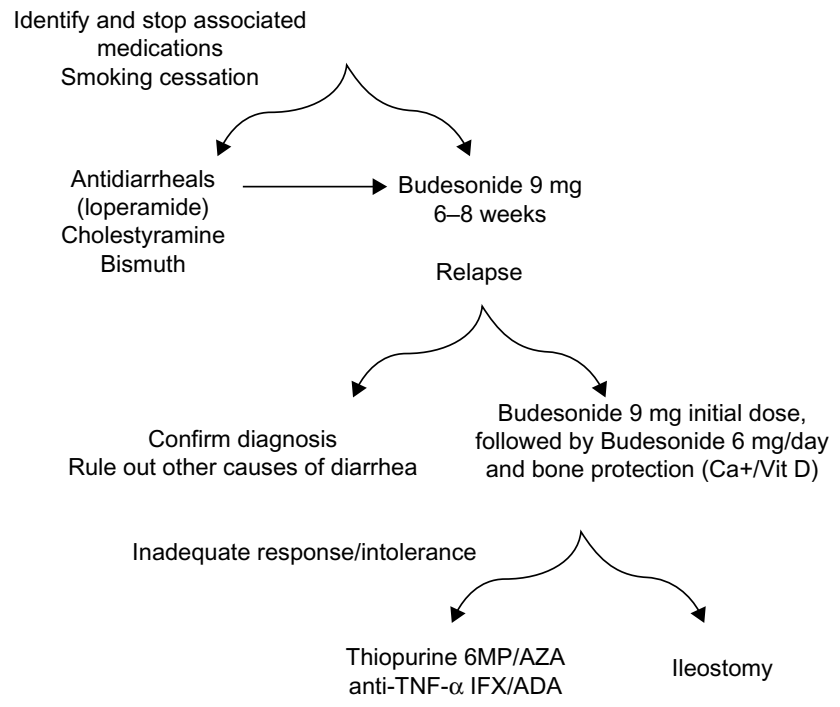

Figure I European Microscopic Colitis Group algorithm for the management of collagenous colitis.

Notes: Adapted by permission of Oxford University Press from Munch A, Aust D, Bohr J, et al. Microscopic colitis: current status, present and future challenges: statements of the European Microscopic Colitis Group. Journal of Crohn's and Colitis. 2012;6(9):932-945. Copyright (C) Oxford University Press. ${ }^{32}$

Abbreviations: 6MP, 6 mercaptopurine; ADA, adalimumab; AZA, azathioprine; IFX, infliximab; TNF, tumour necrosis factor; Vit $D$, vitamin $D$. 
Rates of bile acid malabsorption and the effect of bile acid sequestration were studied in 28 patients with CC, 12 (44\%) had evidence of bile acid malabsorption. Bile acid treatment resulted in rapid resolution of symptoms in 11/12 patients with concomitant bile acid malabsorption compared with 10/15 (67\%) without. ${ }^{85}$ The authors conclude that bile acid malabsorption commonly occurs in CC patients and may contribute to the pathogenesis of colonic inflammation, bile acid therapy should be considered given higher response rates and no serious side effects.

Forty-one patients with LC and 23 with CC were randomized to mesalazine with or without cholestyramine for 6 months. Diarrhea was resolved within 2 weeks in 54 patients $(84.37 \%)$.

In those with $\mathrm{CC}$ clinical and histological remission was achieved in $91.3 \%$ of patients, with better results seen in those randomized to both mesalazine and cholestyramine. ${ }^{86}$

Furthermore, budesonide treatment has been shown to increase bile acid absorption in patients with $\mathrm{CC}$ and this reduction in colonic bile load may in part explain its efficacy. ${ }^{87}$

\section{Amino salicylates}

Previously, there was only anecdotal evidence to support the use of sulfasalazine and mesalazine therapy, but recently they have been studied in controlled trials.

Calabrese et al randomized 64 patients with MC to 6 months' treatment with mesalazine $2.4 \mathrm{~g} /$ day or mesalazine $2.4 \mathrm{~g} /$ day and cholestyramine $4 \mathrm{~g} /$ day. The high-remission rate was seen in both treatment arms, and $85 \%$ of patients with LC and $91 \%$ of patients with $\mathrm{CC}$ were in remission at the end of the study. ${ }^{86}$ However, a placebo-controlled, randomized trial of mesalazine $3 \mathrm{~g} /$ day for 8 weeks as a short-term induction agent was no more efficacious than placebo. ${ }^{77}$

As mentioned in the study by Miehlke et al, of patients with active $\mathrm{CC}$ randomized to budesonide $(9 \mathrm{mg})$, mesalazine ( $3 \mathrm{~g})$, or placebo therapy, rates of remission with mesalamine and placebo were similar after 8 weeks $(32 \%$ and $38 \%$, respectively). ${ }^{77}$ An older study of 163 patients with CC demonstrated remission rates of $40 \%$ with mesalamine or olsalazine. ${ }^{33}$

\section{Antibiotics/probiotics}

There are no controlled data to advocate the use of antibiotics, but metronidazole or erythromycin have previously been used.

Bismuth has anti-inflammatory, antidiarrheal, and antibiotic properties but is not widely available due to concerns regarding nephrotoxicity. ${ }^{81}$ In a small open label trial, bismuth therapy was shown to induce remission of symptoms and disappearance of the collagen band in patients with $\mathrm{CC},{ }^{88}$ treatment was well tolerated with no serious side effects.

Probiotic treatment and the role of the intestinal microbiome requires further assessment. ${ }^{89}$

Madisch et al studied the effect of the Boswellia serrate extract (BSE) on symptoms, QOL, and histology in 31 patients with $\mathrm{CC}$ and found that after 6 weeks, the proportion of patients in clinical remission was higher in the BSE group than in the placebo group (63.6\% vs $26.7 \%$, $P=0.04) .{ }^{90}$ Larger trials are required to confirm the clinical efficacy of BSE in MC.

\section{Immunomodulators}

In the small number of patients with persistent symptoms despite budesonide and antidiarrheal agents, immunomodulator therapy may be considered. . $^{32,52,91}$

Azathioprine induced partial or complete remission in eight of nine patients with $\mathrm{MC}$ in an open study, ${ }^{92}$ furthermore, a retrospective series, demonstrated an overall response rate to thiopurines of $41 \%$ (19 of 46 ), but azathioprine was poorly tolerated accompanied by a high frequency of side effects, leading to treatment cessation. ${ }^{93}$

\section{Methotrexate}

An open case series of nine patients with budesonide refractory CC demonstrated no clinical effect of methotrexate. ${ }^{94}$ Methotrexate therapy $15 \mathrm{mg}$ subcutaneously was administered weekly for 6 weeks and increased to $25 \mathrm{mg}$ thereafter if symptoms persisted. No patient experienced clinical remission or improved QOL and four patients withdrew from the study due to adverse events.

\section{Biologics}

There are no randomized trials studying the role of biologics in the management of CC, but recent case reports have suggested a role for anti-TNF $\alpha$ therapies (infliximab and adalimumab) in CC refractory to budesonide and the author recommends considering biologic therapy before colectomy. ${ }^{95-97}$

\section{Miscellaneous}

Other agents have been studied including octreotide and verapamil, but with no consistent beneficial effect. ${ }^{98,99}$

\section{Surgery}

Surgery should only be considered in those refractory to medical management. ${ }^{100-102}$ Diversion of the fecal stream has 
been shown to induce histopathological remission in $\mathrm{CC}$ but upon restoration of flow the collagen band returned. ${ }^{102}$ This implies that a luminal factor contributes to inflammation and for some patients with refractory disease ileostomy may be an appropriate therapeutic strategy. Surgical options include split ileostomy and subtotal colectomy and success has been reported with total proctocolectomy and ileal pouch anal anastomosis. ${ }^{101,103}$ Considering advances in medical therapy the indication for surgery is limited.

\section{Conclusion}

$\mathrm{CC}$ is an increasingly encountered cause of chronic diarrhea. It is predominantly a benign and self-limiting disorder. The introduction of budesonide has revolutionized treatment of this lesser studied inflammatory bowel disease, however, higher relapse rates are seen upon withdrawal and the management of chronic active colitis remains a challenge. Ongoing trials will address the safety and efficacy of low-dose maintenance therapy. For those with disease unresponsive to budesonide, case reports and case series support the role of biologic agents.

The author recommends screening for concomitant celiac disease and thyroid dysfunction in those with ongoing diarrhea. Smoking cessation is recommended. Patients should be advised to avoid NSAIDs and if possible, discontinue medications associated with MC.

Further insight into the pathogenesis of collagen deposition and the mucosal immunological changes will facilitate improved therapy and may identify biomarkers of disease activity.

\section{Disclosure}

The author reports no conflicts of interest in this work.

\section{References}

1. Fine KD, Seidel RH, Do K. The prevalence, anatomic distribution, and diagnosis of colonic causes of chronic diarrhea. Gastrointest Endosc. 2000;51(3):318-326.

2. Koulaouzidis A, Saeed AA. Distinct colonoscopy findings of microscopic colitis: not so microscopic after all? World J Gastroenterol. 2011; 17(37):4157-4165.

3. Lindstrom CG. 'Collagenous colitis' with watery diarrhoea - a new entity? Pathol Eur. 1976;11(1):87-89.

4. Fine KD, Meyer RL, Lee EL. The prevalence and causes of chronic diarrhea in patients with celiac sprue treated with a gluten-free diet. Gastroenterology. 1997;112(6):1830-1838.

5. Fine KD, Do K, Schulte K, et al. High prevalence of celiac sprue-like HLA-DQ genes and enteropathy in patients with the microscopic colitis syndrome. Am J Gastroenterol. 2000;95(8):1974-1982.

6. Villanacci V, Casella G, Bassotti G. The spectrum of drug-related colitides: important entities, though frequently overlooked. Dig Liver Dis. 43(7):523-528.

7. Cappell MS. Colonic toxicity of administered drugs and chemicals. $A m$ J Gastroenterol. 2004;99(6):1175-1190.
8. Chande N, McDonald JW, Macdonald JK. Interventions for treating collagenous colitis: a Cochrane Inflammatory Bowel Disease Group systematic review of randomized trials. Am J Gastroenterol. 2004;99(12): 2459-2465.

9. O'Toole A, Coss A, Holleran G, et al. Microscopic colitis: clinical characteristics, treatment and outcomes in an Irish population. Int $J$ Colorectal Dis. 2014;29(7):799-803.

10. Benchimol EI, Kirsch R, Viero S, Griffiths AM. Collagenous colitis and eosinophilic gastritis in a 4-year old girl: a case report and review of the literature. Acta Paediatr. 2007;96(9):1365-1367.

11. Camarero C, Leon F, Colino E, et al. Collagenous colitis in children: clinicopathologic, microbiologic, and immunologic features. J Pediatr Gastroenterol Nutr. 2003;37(4):508-513.

12. Gentile NM, Khanna S, Loftus EV Jr, et al. The epidemiology of microscopic colitis in Olmsted County from 2002 to 2010: a population-based study. Clin Gastroenterol Hepatol. 2014;12(5):838-842.

13. Wickbom A, Bohr J, Eriksson S, Udumyan R, Nyhlin N, Tysk C. Stable incidence of collagenous colitis and lymphocytic colitis in Orebro, Sweden, 1999-2008: a continuous epidemiologic study. Inflamm Bowel Dis. 2013;19(11):2387-2393.

14. Tong J, Zheng Q, Zhang C, Lo R, Shen J, Ran Z. Incidence, prevalence, and temporal trends of microscopic colitis: a systematic review and meta-analysis. Am J Gastroenterol. 2015;110(2):265-276; quiz 77.

15. Bonderup OK, Wigh T, Nielsen GL, Pedersen L, Fenger-Gron M. The epidemiology of microscopic colitis: a 10-year pathology-based nationwide Danish cohort study. Scand J Gastroenterol. 2015;50(4): 393-398.

16. Park YS, Baek DH, Kim WH, et al. Clinical characteristics of microscopic colitis in Korea: prospective multicenter study by KASID. Gut Liver. 2011;5(2):181-186.

17. Misra V, Misra SP, Dwivedi M, Singh PA, Agarwal V. Microscopic colitis in patients presenting with chronic diarrhea. Indian J Pathol Microbiol. 2010;53(1):15-19.

18. Hilmi I, Hartono JL, Pailoor J, Mahadeva S, Goh KL. Low prevalence of 'classical' microscopic colitis but evidence of microscopic inflammation in Asian irritable bowel syndrome patients with diarrhoea. BMC Gastroenterol. 2013;13:80.

19. Bohr J, Wickbom A, Hegedus A, Nyhlin N, Hultgren Hornquist E, Tysk C. Diagnosis and management of microscopic colitis: current perspectives. Clin Exp Gastroenterol. 2014;7:273-284.

20. Barmeyer C, Erko I, Fromm A, et al. Ion transport and barrier function are disturbed in microscopic colitis. Ann N Y Acad Sci. 2012;1258: $143-148$.

21. Burgel N, Bojarski C, Mankertz J, Zeitz M, Fromm M, Schulzke JD. Mechanisms of diarrhea in collagenous colitis. Gastroenterology. 2002;123(2):433-443.

22. van Tilburg AJ, Lam HG, Seldenrijk CA, et al. Familial occurrence of collagenous colitis. A report of two families. J Clin Gastroenterol. 1990;12(3):279-285.

23. Lakatos G, Sipos F, Miheller P, et al. The behavior of matrix metalloproteinase-9 in lymphocytic colitis, collagenous colitis and ulcerative colitis. Pathol Oncol Res. 2012;18(1):85-91.

24. Koskela RM, Karttunen TJ, Niemela SE, Lehtola JK, Ilonen J, Karttunen RA. Human leucocyte antigen and TNFalpha polymorphism association in microscopic colitis. Eur J Gastroenterol Hepatol. 2008;20(4):276-282.

25. Erim T, Alazmi WM, O’Loughlin CJ, Barkin JS. Collagenous colitis associated with Clostridium difficile: a cause effect? Dig Dis Sci. 2003; 48(7):1374-1375.

26. Makinen M, Niemela S, Lehtola J, Karttunen TJ. Collagenous colitis and Yersinia enterocolitica infection. Dig Dis Sci. 1998;43(6):1341-1346.

27. Narayani RI, Burton MP, Young GS. Resolution of collagenous colitis after treatment for Helicobacter pylori. Am J Gastroenterol. 2002;97(2): 498-499.

28. Daum S, Foss HD, Schuppan D, Riecken EO, Zeitz M, Ullrich R. Synthesis of collagen I in collagenous sprue. Clin Gastroenterol Hepatol. 2006;4(10):1232-1236. 
29. Aigner T, Neureiter D, Muller S, Kuspert G, Belke J, Kirchner T. Extracellular matrix composition and gene expression in collagenous colitis. Gastroenterology. 1997;113(1):136-143.

30. Stahle-Backdahl M, Maim J, Veress B, Benoni C, Bruce K, Egesten A. Increased presence of eosinophilic granulocytes expressing transforming growth factor-beta1 in collagenous colitis. Scand J Gastroenterol. 2000;35(7):742-746.

31. Andresen L, Jorgensen VL, Perner A, Hansen A, Eugen-Olsen J, Rask-Madsen J. Activation of nuclear factor kappaB in colonic mucosa from patients with collagenous and ulcerative colitis. Gut. 2005;54(4): 503-509.

32. Munch A, Aust D, Bohr J, et al. Microscopic colitis: current status, present and future challenges: statements of the European Microscopic Colitis Group. J Crohns Colitis. 2012;6(9):932-945.

33. Bohr J, Tysk C, Eriksson S, Abrahamsson H, Jarnerot G. Collagenous colitis: a retrospective study of clinical presentation and treatment in 163 patients. Gut. 1996;39(6):846-851.

34. Bohr J, Larsson LG, Eriksson S, Jarnerot G, Tysk C. Colonic perforation in collagenous colitis: an unusual complication. Eur J Gastroenterol Hepatol. 2005;17(1):121-124.

35. Allende DS, Taylor SL, Bronner MP. Colonic perforation as a complication of collagenous colitis in a series of 12 patients. Am J Gastroenterol. 2008;103(10):2598-2604.

36. Tontini GE, Pastorelli L, Spina L, et al. Microscopic colitis and colorectal neoplastic lesion rate in chronic nonbloody diarrhea: a prospective, multicenter study. Inflamm Bowel Dis. 2014;20(5):882-891.

37. Stoicescu A, Becheanu G, Dumbrava M, Gheorghe C, Diculescu M. Microscopic colitis - a missed diagnosis in diarrhea-predominant irritable bowel syndrome. Maedica (Buchar). 2012;7(1):3-9.

38. Patel P, Bercik P, Morgan DG, et al. Prevalence of organic disease at colonoscopy in patients with symptoms compatible with irritable bowel syndrome: cross-sectional survey. Scand J Gastroenterol. 2015;50(7): 816-823.

39. Abboud R, Pardi DS, Tremaine WJ, Kammer PP, Sandborn WJ, Loftus EV Jr. Symptomatic overlap between microscopic colitis and irritable bowel syndrome: a prospective study. Inflamm Bowel Dis. 2013;19(3):550-553.

40. Limsui D, Pardi DS, Camilleri M, et al. Symptomatic overlap between irritable bowel syndrome and microscopic colitis. Inflamm Bowel Dis. 2007;13(2):175-181.

41. Hjortswang H, Tysk C, Bohr J, et al. Health-related quality of life is impaired in active collagenous colitis. Dig Liver Dis. 2011;43(2): $102-109$.

42. Nyhlin N, Wickbom A, Montgomery SM, Tysk C, Bohr J. Long-term prognosis of clinical symptoms and health-related quality of life in microscopic colitis: a case-control study. Aliment Pharmacol Ther. 2014;39(9):963-972.

43. Capurso G, Marignani M, Attilia F, et al. Lansoprazole-induced microscopic colitis: an increasing problem? Results of a prospective case-series and systematic review of the literature. Dig Liver Dis. 2011; 43(5):380-385.

44. Riddell RH, Tanaka M, Mazzoleni G. Non-steroidal anti-inflammatory drugs as a possible cause of collagenous colitis: a case-control study. Gut. 1992;33(5):683-686.

45. Guagnozzi D, Lucendo AJ, Angueira T, Gonzalez-Castillo S, Tenias JM. Drug consumption and additional risk factors associated with microscopic colitis: case-control study. Rev Esp Enferm Dig. 2015;107(6):347-353.

46. Fernandez-Banares F, de Sousa MR, Salas A, et al. Epidemiological risk factors in microscopic colitis: a prospective case-control study. Inflamm Bowel Dis. 2013;19(2):411-417.

47. Vigren L, Sjoberg K, Benoni C, et al. Is smoking a risk factor for collagenous colitis? Scand J Gastroenterol. 2011;46(11):1334-1339.

48. Yen EF, Pokhrel B, Du H, et al. Current and past cigarette smoking significantly increase risk for microscopic colitis. Inflamm Bowel Dis. 2012;18(10):1835-1841.

49. Fernandez-Banares F, de Sousa MR, Salas A, et al. Impact of current smoking on the clinical course of microscopic colitis. Inflamm Bowel Dis. 2013;19(7):1470-1476.
50. Stewart M, Andrews CN, Urbanski S, Beck PL, Storr M. The association of coeliac disease and microscopic colitis: a large population-based study. Aliment Pharmacol Ther. 2011;33(12):1340-1349.

51. Wildt S, Nordgaard-Lassen I, Bendtsen F, Rumessen JJ. Metabolic and inflammatory faecal markers in collagenous colitis. Eur J Gastroenterol Hepatol. 2007;19(7):567-574.

52. Tysk C, Wickbom A, Nyhlin N, Eriksson S, Bohr J. Recent advances in diagnosis and treatment of microscopic colitis. Ann Gastroenterol. 2011;24(4):253-262.

53. Cruz-Correa M, Milligan F, Giardiello FM, et al. Collagenous colitis with mucosal tears on endoscopic insufflation: a unique presentation. Gut. 2002;51(4):600.

54. van Eijk RL, Bac DJ. Mucosal tears and colonic perforation in a patient with collagenous colitis. Endoscopy. 2014;46(Suppl 1) UCTN:E64.

55. Magro F, Langner C, Driessen A, et al. European consensus on the histopathology of inflammatory bowel disease. J Crohns Colitis. 2013;7(10):827-851.

56. O'Mahony OH, Burgoyne M, Going JJ. Specific histological abnormalities are more likely in biopsies of endoscopically normal large bowel after the age of 60 years. Histopathology. 2012;61(6):1209-1213.

57. Geboes K. Lymphocytic, collagenous and other microscopic colitides: pathology and the relationship with idiopathic inflammatory bowel diseases. Gastroenterol Clin Biol. 2008;32(8-9):689-694.

58. Langner C, Aust D, Ensari A, et al. Histology of microscopic colitisreview with a practical approach for pathologists. Histopathology. 2015;66(5):613-626.

59. Tanaka M, Mazzoleni G, Riddell RH. Distribution of collagenous colitis: utility of flexible sigmoidoscopy. Gut. 1992;33(1):65-70.

60. Jessurun J, Yardley JH, Giardiello FM, Hamilton SR, Bayless TM. Chronic colitis with thickening of the subepithelial collagen layer (collagenous colitis): histopathologic findings in 15 patients. Hum Pathol. 1987;18(8):839-848.

61. Carpenter HA, Tremaine WJ, Batts KP, Czaja AJ. Sequential histologic evaluations in collagenous colitis. Correlations with disease behavior and sampling strategy. Dig Dis Sci. 1992;37(12):1903-1909.

62. Chetty R, Govender D. Lymphocytic and collagenous colitis: an overview of so-called microscopic colitis. Nat Rev Gastroenterol Hepatol. 2012;9(4):209-218.

63. Munch A, Langner C. Microscopic colitis: clinical and pathologic perspectives. Clin Gastroenterol Hepatol. 2015;13(2):228-236.

64. Yantiss RK, Odze RD. Optimal approach to obtaining mucosal biopsies for assessment of inflammatory disorders of the gastrointestinal tract. Am J Gastroenterol. 2009;104(3):774-783.

65. Hjortswang H, Tysk C, Bohr J, et al. Defining clinical criteria for clinical remission and disease activity in collagenous colitis. Inflamm Bowel Dis. 2009;15(12):1875-1881.

66. Beaugerie L, Pardi DS. Review article: drug-induced microscopic colitis - proposal for a scoring system and review of the literature. Aliment Pharmacol Ther. 2005;22(4):277-284.

67. Wall GC, Schirmer LL, Page MJ. Pharmacotherapy for microscopic colitis. Pharmacotherapy. 2007;27(3):425-433.

68. Kingham JG. Microscopic colitis. Gut. 1991;32(3):234-235.

69. Sloth H, Bisgaard C, Grove A. Collagenous colitis: a prospective trial of prednisolone in six patients. J Intern Med. 1991;229(5):443-446.

70. Gentile NM, Abdalla AA, Khanna S, et al. Outcomes of patients with microscopic colitis treated with corticosteroids: a population-based study. Am J Gastroenterol. 2013;108(2):256-259.

71. Munck LK, Kjeldsen J, Philipsen E, Fischer Hansen B. Incomplete remission with short-term prednisolone treatment in collagenous colitis: a randomized study. Scand J Gastroenterol. 2003;38(6):606-610.

72. Chande N, MacDonald JK, McDonald JW. Interventions for treating microscopic colitis: a Cochrane Inflammatory Bowel Disease and Functional Bowel Disorders Review Group systematic review of randomized trials. Am J Gastroenterol. 2009;104(1):235-241; quiz 4,42

73. Miehlke S, Madisch A, Voss C, et al. Long-term follow-up of collagenous colitis after induction of clinical remission with budesonide. Aliment Pharmacol Ther. 2005;22(11-12):1115-1119. 
74. Miehlke S, Heymer P, Bethke B, et al. Budesonide treatment for collagenous colitis: a randomized, double-blind, placebo-controlled, multicenter trial. Gastroenterology. 2002;123(4):978-984.

75. Bonderup OK, Hansen JB, Birket-Smith L, Vestergaard V, Teglbjaerg PS, Fallingborg J. Budesonide treatment of collagenous colitis: a randomised, double blind, placebo controlled trial with morphometric analysis. Gut. 2003;52(2):248-251.

76. Stewart MJ, Seow CH, Storr MA. Prednisolone and budesonide for short- and long-term treatment of microscopic colitis: systematic review and meta-analysis. Clin Gastroenterol Hepatol. 2011;9(10):881-890.

77. Miehlke S, Madisch A, Kupcinskas L, et al. Budesonide is more effective than mesalamine or placebo in short-term treatment of collagenous colitis. Gastroenterology. 2014;146(5):1222-1230. e1-e2.

78. Baert F, Schmit A, D’Haens G, et al. Budesonide in collagenous colitis: a double-blind placebo-controlled trial with histologic follow-up. Gastroenterology. 2002;122(1):20-25.

79. Madisch A, Heymer P, Voss C, et al. Oral budesonide therapy improves quality of life in patients with collagenous colitis. Int J Colorectal Dis. 2005;20(4):312-316.

80. Miehlke S, Hansen JB, Madisch A, et al. Risk factors for symptom relapse in collagenous colitis after withdrawal of short-term budesonide therapy. Inflamm Bowel Dis. 2013;19(13):2763-2767.

81. Munch A, Bohr J, Miehlke S, et al. Low-dose budesonide for maintenance of clinical remission in collagenous colitis: a randomised, placebo-controlled, 12-month trial. Gut. 2014. Epub 2014 Nov 25.

82. Sarikaya M, Sevinc A, Ulu R, Ates F, Ari F. Bismuth subcitrate nephrotoxicity. A reversible cause of acute oliguric renal failure. Nephron. 2002;90(4):501-502.

83. Fernandez-Banares F, Salas A, Esteve M, Espinos J, Forne M, Viver JM. Collagenous and lymphocytic colitis. Evaluation of clinical and histological features, response to treatment, and long-term follow-up. Am J Gastroenterol. 2003;98(2):340-347.

84. Ung KA, Kilander A, Nilsson O, Abrahamsson H. Long-term course in collagenous colitis and the impact of bile acid malabsorption and bile acid sequestrants on histopathology and clinical features. Scand J Gastroenterol. 2001;36(6):601-609.

85. Ung KA, Gillberg R, Kilander A, Abrahamsson H. Role of bile acids and bile acid binding agents in patients with collagenous colitis. Gut. 2000;46(2):170-175

86. Calabrese C, Fabbri A, Areni A, Zahlane D, Scialpi C, Di Febo G. Mesalazine with or without cholestyramine in the treatment of microscopic colitis: randomized controlled trial. J Gastroenterol Hepatol. 2007;22(6):809-814.

87. Bajor A1 KA, Gälman C, Rudling M, Ung KA. Budesonide treatment is associated with increased bile acid absorption in collagenous colitis. Aliment Pharmacol Ther. 2006;24 (11-12):1643-1649.

88. Fine KD, Lee EL. Efficacy of open-label bismuth subsalicylate for the treatment of microscopic colitis. Gastroenterology. 1998;114(1):29-36.
89. Wildt S, Munck LK, Vinter-Jensen L, et al. Probiotic treatment of collagenous colitis: a randomized, double-blind, placebo-controlled trial with Lactobacillus acidophilus and Bifidobacterium animalis subsp. Lactis. Inflamm Bowel Dis. 2006;12(5):395-401.

90. Madisch A, Miehlke S, Eichele O, et al. Boswellia serrata extract for the treatment of collagenous colitis. A double-blind, randomized, placebo-controlled, multicenter trial. Int J Colorectal Dis. 2007; 22(12):1445-1451.

91. Pardi DS, Kelly CP. Microscopic colitis. Gastroenterology. 2011;140(4):1155-1165.

92. Pardi DS, Loftus EV Jr, Tremaine WJ, Sandborn WJ. Treatment of refractory microscopic colitis with azathioprine and 6-mercaptopurine. Gastroenterology. 2001;120(6):1483-1484.

93. Munch A, Fernandez-Banares F, Munck LK. Azathioprine and mercaptopurine in the management of patients with chronic, active microscopic colitis. Aliment Pharmacol Ther. 2013;37(8): 795-798.

94. Munch A, Bohr J, Vigren L, Tysk C, Strom M. Lack of effect of methotrexate in budesonide-refractory collagenous colitis. Clin Exp Gastroenterol. 2013;6:149-152.

95. Esteve M, Mahadevan U, Sainz E, Rodriguez E, Salas A, FernandezBanares F. Efficacy of anti-TNF therapies in refractory severe microscopic colitis. J Crohns Colitis. 2011;5(6):612-618.

96. Pola S, Fahmy M, Evans E, Tipps A, Sandborn WJ. Successful use of infliximab in the treatment of corticosteroid dependent collagenous colitis. Am J Gastroenterol. 2013;108(5):857-858.

97. Munch A, Ignatova S, Strom M. Adalimumab in budesonide and methotrexate refractory collagenous colitis. Scand J Gastroenterol. 2012;47(1):59-63.

98. Fisher NC, Tutt A, Sim E, Scarpello JH, Green JR. Collagenous colitis responsive to octreotide therapy. J Clin Gastroenterol. 1996;23(4): 300-301.

99. Scheidler MD, Meiselman M. Use of verapamil for the symptomatic treatment of microscopic colitis. J Clin Gastroenterol. 2001;32(4) 351-352.

100. Bowling TE, Price AB, al-Adnani M, Fairclough PD, Menzies-Gow N, Silk DB. Interchange between collagenous and lymphocytic colitis in severe disease with autoimmune associations requiring colectomy: a case report. Gut. 1996;38(5):788-791.

101. Williams RA, Gelfand DV. Total proctocolectomy and ileal pouch anal anastomosis to successfully treat a patient with collagenous colitis. Am J Gastroenterol. 2000;95(8):2147.

102. Jarnerot G, Tysk C, Bohr J, Eriksson S. Collagenous colitis and fecal stream diversion. Gastroenterology. 1995;109(2):449-455.

103. Munch A, Soderholm JD, Wallon C, Ost A, Olaison G, Strom M. Dynamics of mucosal permeability and inflammation in collagenous colitis before, during, and after loop ileostomy. Gut. 2005;54(8): 1126-1128.
Clinical and Experimental Gastroenterology

\section{Publish your work in this journal}

Clinical and Experimental Gastroenterology is an international, peerreviewed, open access journal, publishing all aspects of gastroenterology in the clinic and laboratory, including: Pathology, pathophysiology of gastrointestinal disease; Investigation and treatment of gastointes tinal disease; Pharmacology of drugs used in the alimentary tract;

\section{Dovepress}

Immunology/genetics/genomics related to gastrointestinal disease. This journal is indexed on CAS. The manuscript management system is completely online and includes a very quick and fair peer-review system. Visit http://www.dovepress.com/testimonials.php to read real quotes from published authors. 